\title{
STUDY ON THE SERVICE QUALITY E-RETAILING VARIABLES AFFECTING BRAND LOYALTY
}

\section{Art Shala, Driton Balaj}

(1) Marketing Department, University Kadri Zeka, Gjilan, Kosovo, (2) Finance Department, University Hasan Prishtina, Prishtina, Kosovo

Art Shala

Marketing Department, University Kadri Zeka, Gjilan, Kosovo artshala@gmail.com

\section{Article info \\ Paper category: Preliminary Paper Remark: Resubmitted after Revision: 24.12.2018. \\ JEl classification: L81 DOI: $10.32728 /$ ric. $2018.44 / 3$}

Keywords

Brand Loyalty; Online Service Quality; Local vs Global; Fuzzy-Sets 


\section{ABSTRACT}

Purpose. The study aims to study four attributes of the electronic retailing service quality [website design, reliability/fulfillment, security/privacy and customer service] based on the implications each one of them has towards brand loyalty [being measured through intentions to repurchase from the same brand on upcoming occasions and customer incentives to pay a price premium for the brand]. This process in two contexts, when respondents are faced with a local vs global brand.

Design/Methodology/Approach. Through literature review the study has used the model of mapping electronic service quality variables introduced by Wolfinbarger and Gilly (2003) in their eTail Quality model. Related to data collection we have conducted two focus groups each being prompted with local and global renown brands, respectively. Considering that the study aims to measure perceptions, and knowing that the best way to express them is through linguistic terms, which is the way humans express their feelings on daily basis, the analysis is based on fuzzy logic by using triangular fuzzy sets as means of analysis. The process through the analysis phase has followed the (i) fuzzification process, where linguistic terms have been converted to triangular fuzzy sets, (ii) fuzzy averaging to find group opinions, (iii) clarifying weak and/or strong conditions in between the importance and satisfaction degrees, lastly (iv) defuzzification process in order to convert triangularfuzzy sets in linguistic terms.

Findings and Implications. The analysis suggests that when customers are faced with global brands, service quality elements such as website design, customer service and reliability/fulfillment are good predictors for the creation of behavioral intents towards the brand. Whereas when customers faced with local brands, service quality elements such as security/privacy, reliability/fulfillment and website design, have high implications towards customers' behavioral intents.

Limitations. The study represents an innovative approach to measuring service quality variables in the apparel purchase online context. Due to its generic nature as a model the conceptual framework and methods of analysis could be tested in other industries, apart from the apparel online purchase. Furthermore, in order to enforce external validity, the study is recommended to be replicated within the same or other contexts.

Originality. This scientific paper presents an innovative approach to measuring online service quality in the apparel industry. Furthermore, the understanding of underlying factors impacting customers purchase online from local or global brands makes it unique in its nature for the context applied. The use of fuzzy logic and triangularfuzzy sets has allowed the research to use linguistic measurements (which belong to the nature of how humans' express feelings) and their conversion in fuzzy triangular sets allowing for deeper analysis in descriptive and predictive statistics without comprising the reliability of either of them. 


\section{INTRODUCTION}

During the last 15 years, there has been immense growth on the apparel industry providers offering products online. This segment of the market has seen high growth and is still considered on having potential to grow more. With the existence of global providers there have been as well local providers offering such services. This has mainly been as a consequence of better understanding local fashion trends; feature that has caused retailers to be more efficient with their stock. Offering good service quality appears to be essential for success in the online environment. From the organizations perspective, the relevance of these issues, mostly regards to how the service quality attributes impact behavioral intents that customers develop throughout their experiences online. The importance of the online service quality on the cases when customers buy from local or global brands formalizes the ground for the objectives that this research aims to study:

- identify key service quality attributes that impact upcoming repurchasing behavioral intents;

- identify key service quality attributes that incentivize customers to pay a price premium;

- assess the relationships between the service quality attributes and behavioral intents in situations where customers are purchasing from local versus global brands.

A plausible answer to these questions is beneficial in contributing to the current academic discussion in the area; as well as for assisting practitioners operating in this field, taking into account that this relationship directly affects their profitability on the long run.

\section{CONCEPTUAL FRAMEWORK}

In order to answer the questions this study poses, we proceed with presenting previously conducted research on the constructs of the study, being brand awareness, brand loyalty and e-commerce service quality attributes. 
Figure 1.: The Conceptual Model

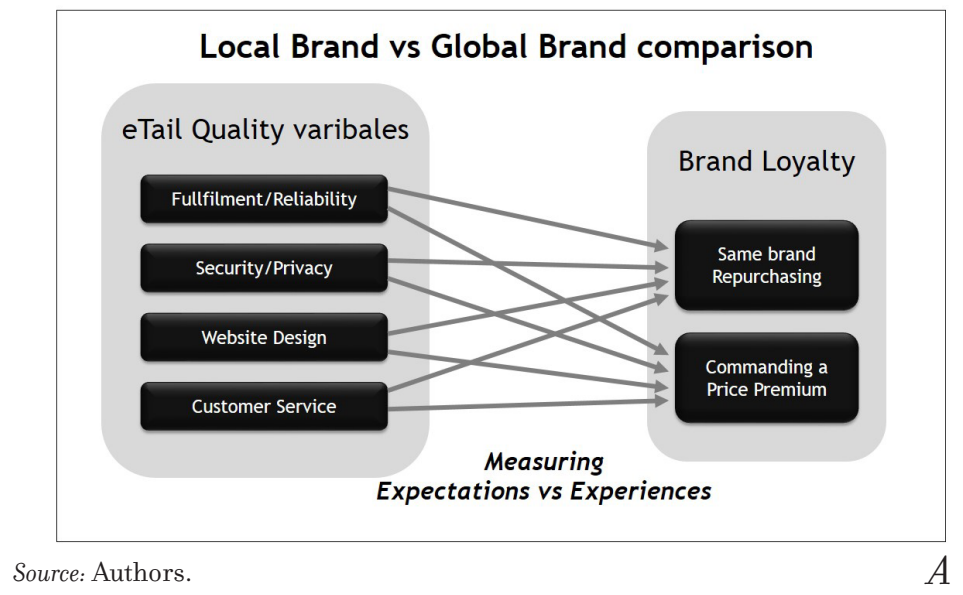

\subsection{Brand Awareness [local versus global brands] and brand loyalty and the e-commerce}

In a transaction there are always risks that are encountered between the buyer and the seller, where brands are found to have a high importance benefit as risk reducers (Roselius 1971). Based on research conducted by Keller (2012), brands are regarded to reduce risk perceptions in a buying decision. According to Pan et al (2012), customers perceive the online environment to be more risky due to the non-physic existence of the stores. Consequently, in the online, they base their buying decision on brands that they know, hence the role of known brands locally or known brands at a global level. The role of local versus global brand offering similar services, could be seen from different prisms affecting customers. The self-identification or being part of owns community could be seen as main elements empowering local brands. Previous research has proved that in developed countries consumers prefer brands with strong local connections (Zhang and Khare 2009). Whereas, this relationship has been questionable in developing countries, considering their aspiration for further towards developed countries culture and life style (Chiu 2015). Global brands are considered brands that market to several countries across the world. Strong associations that are leveraged by global brands are: good perceived quality, level of prestige and psychological benefits (EM Steenkamp, Batra, and Alden 2003).

Based on these determinants related to brand awareness and the benefits of local vs global brands, we assume brand awareness and country of origin to play a crucial role in the perceptions towards service quality attributes that this research aims to study. According to Oliver (1999), loyalty is described as the "commitment to rebuy or re-patronize a preferred product/service consistently in the future, thereby causing repetitive same-brand or same brand-set purchasing, despite situational 
influences and marketing efforts, having the potential to cause switching behavior". Through this definition of loyalty, the main emphasis is put in the re-purchasing of the same-brand or brand-set regardless of the risks from external factors influencing the switching behavior to another brand. With regards to the online world, research has shown that an increase of $5 \%$ in customer retention, consequentially affects profit growth from $25 \%$ to $90 \%$ within the fifth year (Schefter and Reichheld 2000). This essential growth on customer retention is associated to a better service offered online which affects customers' behavioral intents to revisit the website. In this study, elements of importance are related to the behavioral loyalty, that Keller (2012) defines in terms of repeated purchases, and attitudinal attachment. Acquiring customers via the web is costly and, since the competition is just a mouse click away, customer e-loyalty appears essential in an economic as well as a competitive sense (Gustafsson et al. 2005). Thus, e-loyalty is defined as the "consumer's favorable attitude toward the e-retailer that results in repeat buying behavior" (Srinivasan, Anderson, and Ponnavolu 2002). Service quality level is confirmed to affect the behavioral intents that customers tend to develop with the brand (Zeithaml, Berry, and Parasuraman 1996). Brand loyalty has been proved to be affected by the level of brand awareness but this process is considered to be mediated by the impact that perceived quality that customers expect to receive from a global vs local brand (Roy and Chau 2011). Offering customers a good service quality online is believed to be a good predictor towards pushing customers to repurchase from the same brand and incentivize them into paying a price premium for the services.

Electronic commerce is defined as 'all electronically mediated information exchanges between an organization and its external stakeholders' (Chaffey 2007).

According to Bakos (1998), the reasons behind e-commerce's success lie upon its successful leverage of information technologies to offer a platform where there is an increased effectiveness and decrease in transaction costs consequentially leading to an increase in efficiency. According to Tassabehji and Ebrary (2003), customer's benefits that accrue when using e-commerce are: $24 / 7$ access, ease of switching from one supplier to another through a live price comparison between the offerings and a wider variety of products being offered. In this study, the main focus would be on the comparison between two similar e-commerce platforms. ASOS is an international apparel fashion retailer founded in 1999, with coverage across Europe, Asia and USA (ASOS 2015); and on the other hand OXYS founded in 2012, which is an fashion electronic retailer and offers its products and services within Albania and Kosovo. These two were taken as an example considering the high awareness they enjoy across Tirana, Albania. One of the main characteristics they share across each other, are that they sell goods through e-commerce platforms. The impact of how one customer may judge the service quality variables and how he/she might become brand loyal towards the brand, is considered to be mediated by the brand awareness and associations that the brand offers. 


\subsection{Measuring Electronic Service Quality [eTail Quality]}

Positioning the consumer as the focal point of the study and offering a good service quality online is a key determinant in fostering web sales and profits for the company. In addition to the quality of goods or services offered, other determinants in being successful are the website presence and a low price of goods or services offered. Studies on the online environment and the service quality offered in e-commerce platforms have been researched from different perspectives: satisfaction with the website (Alpar 1999, Blut et al. 2015) website success (Liu and Arnett 2000); intention to purchase and the intention to revisit (Loiacono, Watson, and Goodhue 2007); online experience (Novak, Hoffman, and Yung 2000) and customer loyalty (Srinivasan, Anderson, and Ponnavolu 2002). All these studies pinpoint attributes of the service quality online, but lack the general sense of the service quality measurement, from a pre-purchase, purchase to post-purchase review of the process. An overall evaluation of the service quality online has been proposed by Wolfinbarger and Gilly (2003), called electronic retailing service quality [eTail Quality], which focuses into measuring the service quality in an e-commerce platform holistically at all stages of the customer interaction with the website. Depicting the whole process on purchasing goods online from the information search, service provided through the navigation on the website, the process of ordering the goods, potential customer service correspondence between the seller and buyer, finalized by the procedure of shipping the product to the buyer. Dimensions measuring the etail quality are: fulfillment and reliability, website design, customer service and security/privacy. According to Parasuraman and Berry (1985), service quality measures the gap between what consumers expect from the service and what their perceptions after experiencing the service are. The gap between the two measures presents the perceived service quality. Therefore perceived quality signifies an overall attitude; judgment towards the service quality for its superiority compared to competitors (Zeithaml 1988). According to Chien and Tsai (2000), from a customer's stand point expectations and perceptions characterize the difference between the importance degree related to the expected quality and the satisfaction degree corresponding from the perceived experience. Seemingly the importance and significance of a good service quality offered in offline or online, appears to have a huge implication of the company's success.

Fulfillment/reliability as defined by Wolfinbarger and Gilly (2003) is "[a] the accurate display and description of a product so that what customers receive is what they thought they ordered, and [b] delivery of the right product within the time frame promised." So, fulfillment and reliability is a consequence of a couple of implications such as the representation of the adequate product which is shown on the website and what is going to be delivered; technology which is used in the e-commerce framework and its functionality of receiving orders correctly and forwarding these orders in time; and finally the relationship between the online retailer and the deliv- 
ery services in order that the consumer receives the products that are purchased at a certain time within the deadline that was stated in the website.

Website design includes all elements relevant to the customer's experience with the website [except for customer service]. It includes dimensions as navigation, information search, order processing, appropriate personalization and product selection. According to Schaffer (2000), it is the inability to navigate a website and failure to find their way through, which represents 3०\% of customers who leave the website without purchasing anything. According to Pastrick (1997), elements such as fast loading, uncluttered and easy to navigate websites characterize the best dimensions for a satisfying e-commerce experience. Because, e-commerce platforms that are characterized with these elements offer the benefit for consumers to shorten their shopping time compared to the offline world. In order to characterize website design these were the guidelines: Very user friendly navigation; Huge caching ability, speed optimized website, allowing a very quick navigation within the website; Once creating a user and sharing your preferred styles, the website automatically suggests goods that you might be interested in purchasing; A one-click option to purchase a product(Rosen and Purinton 2004).

Customer service refers to the care that the online retailer has shown towards situations where customers face challenges with the framework. According to Wolfinbarger and Gilly (2003), employees' skills or technological tools that offer prompt solutions to customers facing these challenges play a crucial role at this point. Thinking of it, the customer service is regarded as the process of not allowing any problem occurrence within the system, however if challenges are faced, the efficiency and effectiveness to solve these issues is measured. With the social media frameworks people can easily share bad reviews to thousands of people within seconds. Therefore, the impact that customer service has on the whole experience and behavioral consequences towards brand loyalty is considered of immense importance. Customer service is defined in this study by Wolfinbarger and Gilly (2003) as the "responsive, helpful, willing service that responds to customer inquiries quickly."

To measure the customer service offered online these characteristics are used: The option of contact us for any issue that you face with the framework or shipping issues is available; A phone line is given, offering assistance for any questions that the consumer might have; An immediate chat option is offered, so that customers get an immediate response regarding the challenges that they are facing.

Security/privacy is related to the level of credit card payments security and privacy of users shared information. Even though privacy and security are used as an expression together, they tackle different elements within the experience online. Privacy is related to the safety level of how information is gathered from customers, how the data are stored and finally for what purposes the data will be used. Another point to make with regards to privacy is that of asking from the visitor of the platform on approving the data usage conditions (Friedman, Khan Jr, and Howe 2000). Whereas 
security is related to the financial risks that consumers might face throughout their online transactions. Such as how the credit card information will be handled and the protection level of conserving that information from vulnerable acts (Wolfinbarger and Gilly 2003). According to Hoffman, Novak, and Peralta (1999) information privacy is listed as the top concern for web visitors. Based on his study, people that do not buy online appear not to be taking this decision based on functional reasons but it is mostly with regards to the frightening fact of giving personal information away. Miyazaki and Fernandez (2001), consider that privacy and security issues represent the crucial barriers for the consumers not using e-commerce activities. Moreover, potential online customers are very aware of the implications of privacy and security in an environment which contains potential threats for vulnerability acts (Culnan and Armstrong 1999).

With regards to characterizing the Security and Privacy this elements are used: Personal information is gathered only when information is given by the consumer [such as when you open your account] and through cookies, in order to have better results on the recommended products or offering the 1-click purchase option; We only share personal information related to specific transaction when the product needs to pass through one of our affiliated parties. The information shared is strictly connected only to information concerning that transaction; With regards to the security, information given from the customers' side is encrypted with advanced software named Secure Sockets Layer [SSL], offering a high level security; Only the four digits of the credit card can be seen when a customer wants to buy a product, in order to decrease the probability of vulnerability acts by third parties; And finally, all the security and privacy terms and conditions are during the whole time accessible through the website.

\section{RESEARCH METHODOLOGY}

The main focus of this study is on measuring the service quality offered in ecommerce platforms and the implications it has on behavioral intents to repurchase from the brand and pay a price premium for it based on the case of dealing with local or global brands. The relation between the two is studied under two conditions, being the importance degree and the satisfaction degree (Chien and Tsai 2000). In order to measure the possible implications of local vs global brand we apply the same research in two focus groups, where [i] one analyzes the implications when consumers purchase from a local brand, OXYS is taken as an example in this case and [ii] analyzes the implications when participants purchase from a global brand, ASOS will be used as the brand to study. Rihoux and Ragin (2009), discussed the need to set up sufficiently comparative cases which share similar patterns is essential for a research aiming on drawing parallels of comparison between them. In order to have a similar pool of participants in the experiment, the case selection procedure covered two phases: 
First phase: A homogenous pool of participants was demanded with regards to experiences online. During this phase 70 people were contacted, in order to be presented with the research, and whether they showed interest in being part of this study. In order to be eligible as a participant in the study a person should have fulfilled the below mentioned criteria:

- Every participant needed to have at least purchased online three times during the last year;

- Every participant should be familiar with both OXYS and ASOS brand;

- Every participant needed to have spent at least 50 Euros on their online purchases throughout 2015;

- Every participant needed to have previous experience on buying apparel goods online.

From the total number of 70 cases that were contacted in Tirana [Albania], demanding a reply from the ones that fulfilled the above mentioned criteria, 19 replied to the email, admitting their interest in the study. A certain date was set when and where the experiment would take place. Furthermore, only 14 were available on that specific date and time.

Second phase: The 14 participants were assigned randomly into the two groups. A bowl of mixed papers having written a unique number in them varying from 1 to 14. was used. The participants were asked to get a paper from the bowl and tell the number. Participants having numbers from 1 to 7 were assigned to Group 1 [OXYS group] and the participants having numbers from 8-14 were assigned to Group 2 [ASOS group].

Conducting experiments seems to be the best way on finding the cause effect relations between study constructs (Christensen, Johnson, and Turner 2011). The study controls for internal validity by setting out a strict guideline for participants in order to be part of the research, which is elaborated below. During the experiment the participants are randomly assigned to the focus groups. Having on focus the measurement of linguistic terms such as importance degree and satisfaction degree, the challenge was on selecting the appropriate method of analysis. Customer perceptions are expressed in linguistic terms and expecting respondents to provide objective response in continuous data is a bit a challenge (Chien and Tsai 2000). On the other hand, fuzzy logic and fuzzy sets have appeared to be very significant methods on using linguistic terms as inputs for approximate reasoning (Zimmermann 2001). As well they have proved to be very effective in situations of uncertainty such as is the case when customer perceptions are studied (Zadeh 2002). The strong point of fuzzy logic and fuzzy sets lies upon the fact of offering a linguistic degree of vagueness as a metric which in real life situations is a common case (Bojadziev and Bojadziev 2007). Measuring customer perceptions based on fuzzy logic seems to be more objective for this particular study, thus I decide to proceed by utilizing this method. 


\section{THE FUZZY SETS THEORY AND FUZZY ARITHMETIC}

As a theory, it has had a wide application on research fields as: computer science, decision theory, logic, management science, operations research as well as pattern recognition (Bojadziev and Bojadziev 2007). Conventional or crisp sets are seen as the primates of fuzzy sets. Zimmermann (2001), referred to crisp sets as " $a$ collection of elements or objects that can be finite countable, or over countable". The pioneer in fuzzy logic and fuzzy sets, Lotfi Zadeh (Jacoby and Kyner 1973) referred to this traditional logic as when "the complexity of a system increases, our ability to make precise and yet significant statements about its behavior diminishes until a threshold is reached beyond which precision and significance [or relevance] become almost mutually exclusive characteristics."

In real life, this is rarely the case, considering that mostly an attribute can be considered as member for a certain amount to a certain group and as well there could be a possibility of being member to another group. The downfall of the crisp set theory and bivalent logic that probability theories use are that, in real life, variables might be partly members of a set or outcome (Rihoux and Ragin 2009). The theory of fuzzy sets allows partial membership to a given condition between a full nonmember denoted by $\circ$ and a full member denoted by 1 ; in order to describe the gradual transitions between the two continuums. As a theory it consists of this strong point that based on the analysis, it allows an attribute or condition to be a partial member of the outcome (Zimmermann 2001). For ex. if A is the set of importance degree between the eTail Quality attributes and brand loyalty types, fuzzy set $\tilde{A}$ represents the set of ordered pairs $\widetilde{A}=\left\{\left(x, \mu_{A}(x)\right) \mid x \in X\right\}$ where $\mu_{A}(x)$ is the membership function of $\mathrm{x}$ in $\tilde{A}$. This membership function can vary in between the two continuums of being a nonmember up to being a full member of the outcome that is studied (Zadeh 1965).

In this study the two conditions importance degree and satisfaction degree could be considered as vague or with a degree of vagueness and hardly conceptualized (Chien and Tsai 2000). The condition of importance degree between eTail Quality attributes and brand loyalty types; through fuzzy sets I can offer the glimpse on understanding the partial membership that the attribute might have on the outcome. The same holds for the satisfaction degree which is analyzed in this study.

There are two major reasons why this theory applies in discovering the puzzle in this work. This range is given in linguistic terms in order not to lose its objectivity, when data is collected. The benefit of fuzzy sets is that it enjoys the possibility on using the same arithmetic calculations as conventional sets such as union, intersection and negation (Rihoux and Ragin 2009), which provide a good background on finding cause-effect relations and pattern recognition in the variables that are studied. Another reason for using this method on this study would be the lack of having a defined parameter on measuring importance degree and satisfaction degree (Chien and Tsai 2000). Linguistic terms as importance and satisfaction are not deterministic com- 
pared to a linguistic term as height, which can be measured based on a certain set of scales such as meter, feet etc. The fuzziness on defining the concepts makes the conditions that are being studied to be adequate for a fuzzy sets study.

The bases of fuzzy arithmetic imply that, let the universe of discourse $\mathrm{X}$ be the subset of real number $\mathrm{R}$ where $X=\left\{x_{1}, x_{2}, x_{3}, \ldots, x_{n}\right\}$. A fuzzy set $\widetilde{\mathrm{A}}=\left\{\left(x, \mu_{A}(x)\right) \mid x \in X\right.$ in $X$ is a set of ordered pairs where $\mu_{A}(x)$ is called the membership function where $\mu_{A}(x): X \rightarrow[0,1]$.

Through the various types of fuzzy number representations, this study uses the triangular fuzzy numbers which are proved to have wide applications in social sciences (Bojadziev and Bojadziev 2007). The membership degree of importance and satisfaction conditions, in terms of triangular fuzzy number Figure 1., lays between $a_{1}$, meaning full nonmember of a set; $a_{2}$ denoting a full member of the set and $a_{3}$ denoting full nonmember of the set. The triangular fuzzy numbers are denoted by $\widetilde{A}=\left(a_{1}, a_{2}, a_{3}\right)$. The $\mathrm{v}_{\mathrm{A}}$ score in Figure 1., is the point that divides the bounded area of a triangular fuzzy number $\widetilde{A}$ into two equal parts.

Figure 2.: A triangular fuzzy number

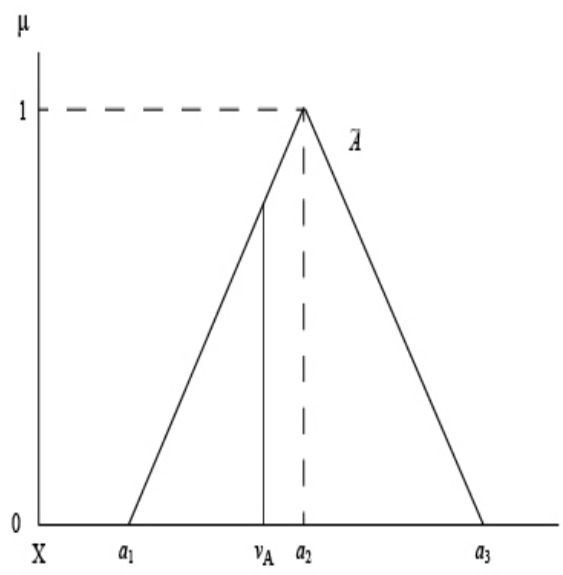

Source: Bojadziev and Bojadziev (2007).

Using the same method as used by Chien and Tsai (2000), which applies based on previous findings from Dubois and Prade (1985), Peter, Churchill Jr, and Brown (1993), Klir and Yuan (1995) I proceed on understanding the study and analyzing the data through four stages, being:

(1) Firstly, since importance degree and satisfaction degree could be considered as vague terms of measurement Chien and Tsai (2000), in this study we fuzzify these two degrees, which are shown as $\mu_{A}$ [for the importance degree] and $\mu_{B}$ [for the satisfaction degree]. These two membership scores correspond 
to Group 1 respondents. The same procedure is applied to Group 2 and create membership scores presented by $\mu_{C}$ for importance degree and and $\mu_{D}$ for the satisfaction degree. The process of fuzzifying the importance degree and satisfaction degree is shown in equation. (1). The same procedure is applicable for $\mu_{B}, \mu_{C}$, and $\mu_{D}$.

$\mu_{A}(x)= \begin{cases}y_{a}^{L}(x)=\frac{x-a_{1}}{a_{2}-a_{1}}, & a_{1} \leq x \leq a_{2} \\ y_{a}^{R}(x)=\frac{x-a_{3}}{a_{2}-a_{3}}, & a_{2} \leq x \leq a_{3} \\ 0, & \text { otherwise }\end{cases}$

(2) In order to understand the general descriptive part within the surveyed groups I use the average fuzzy number denoted by $\mathrm{A}_{\text {ave }}$ for the $n$ triangular numbers, equation (2). The same is done to membership scores for B, C and D sets. Graphical presentation of the procedure is shown in Figure 2.

$\widetilde{A}=A_{\text {ave }}=\frac{\widetilde{A}_{1}+\widetilde{A}_{2}+\ldots+\widetilde{A}_{n}}{n}=\frac{\left(\sum_{i=1}^{n} a_{1}^{(i)}, \sum_{i=1}^{n} a_{2}^{(i)}, \sum_{i=1}^{n} a_{3}^{(i)},\right)}{n}=\left(a_{1}, a_{2}, a_{3}\right)$

Figure 3.: Fuzzy Averaging
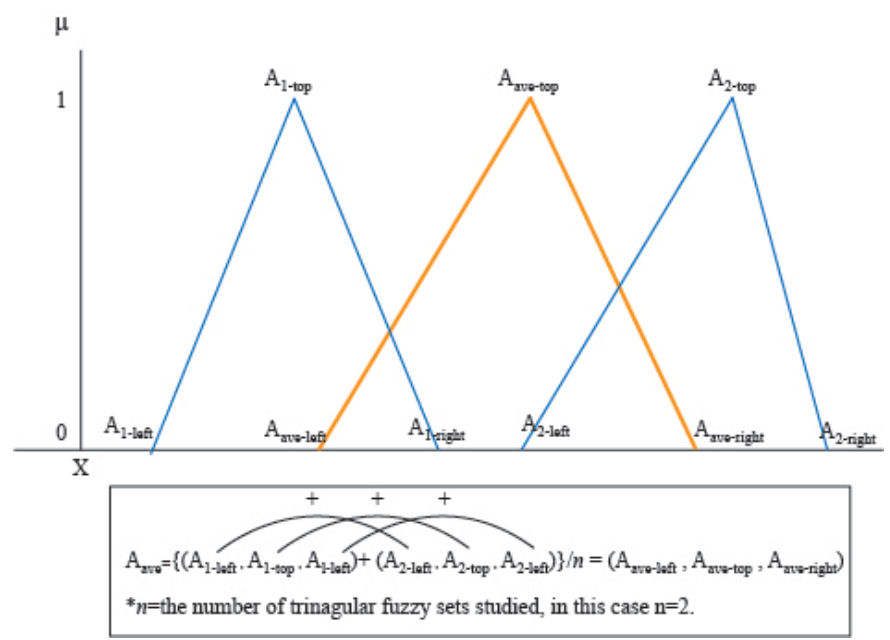

Source: Chien and Tsai (2000). 
(3) Clarify weak and/or conditions for each etail quality attribute with regards to the two types of brand loyalty equations (3) - (5). Furthermore understanding the implications that local brands vs global brand has on positioning a specific attribute as sufficient for the outcome to happen.

$$
\begin{aligned}
& v_{A}=\left(a_{1}+2 a_{2}+a_{3}\right) / 4 \\
& v_{B}=\left(b_{1}+2 b_{2}+b_{3}\right) / 4 \\
& v=v_{B}-v_{A}
\end{aligned}
$$

Through this analysis I am after to find whether the importance or satisfaction degrees are greater or smaller when compared to one another. Using the theory from Chien and Tsai (2000), In the findings section I will present which eTail Quality attribute appears to be sufficient for behavioral intentions to happen.

(4) Defuzzifying sets which are of interest to the study. As the last step of the process I use the v scores equations (3) and (4), to defuzzify the sets, and give them the approximate linguistic term. This type of deffuzification procedure has been proved to work very well in studies where triangular fuzzy numbers are used (Zimmermann, 2001; Chien and Tsai, 2000; Bojadziev and Bojadziev, 2007), which is the case in this study.

\section{ANALYSIS}

This section will firstly give the descriptive information on the samples being: gender and value of online purchases during 2015 for the focus group participants. Then, the analysis deepens into interpreting linguistic terms into fuzzy sets, aggregation of group opinions and finally the mathematical analysis to see the differences between the trends in the samples and lastly generalize from the sample.

In terms of group composition, the Group 1 [OXYS] consisted of three males and four females, whereas Group 2 [ASOS] consisted of two males and five females. In terms of the value of online purchases throughout 2015, in Group1, one [or 14\% of all cases] denoted spending $500 €$ to $1000 €$ during 2015 , and six [or $86 \%$ of all cases] denoted spending more than $1000 €$ during 2015 . In Group 2, two [or $29 \%$ of all cases] denoted spending between $500 €$ to $1000 €$ during 2015 , and five [or $71 \%$ of all cases] proclaimed spending more than $1000 €$. Overall in the two groups as a percentage, $21 \%$ spent between $500 €$ to $1000 €$ during 2015 ; whereas $79 \%$ spent more than 1000 euro during the same year.

In order to analyze the linguistic results extracted during the focus groups, the linguistic terms are converted into fuzzy sets. Let the triangular fuzzy number that signifies the $i^{\text {th }}$ consumer's linguistic importance degree of etail quality attributes having as an outcome the two brand loyalty types and be one that is the $i^{\text {th }}$ consumer's linguistic satisfaction degree of etail quality attributes having as an outcome the two 
brand loyalty types. $k$ denotes the $k^{\text {th }}$ etail quality attribute; $j$ represents the $j^{\text {th }}$ type of brand loyalty. In terms of sets the $i=1,2,3, \ldots, n$; representing consumer's linguistic term, where $n$ is the number of cases that were analyzed, $k=1,2,3, \ldots, p$; where $p$ denotes the number of etail quality attributes and $j=1,2,3, \ldots, m$; where $m$ denotes the number of brand loyalty types. In this case in hand, since there are two groups consisting each of 7 participants, each group consists of these numbers: $i=\eta, k=4$ and $j=2$; so we have seven cases, four different etail quality attributes and two types of brand loyalty.

The same numbers of $i=\eta, k=4$ and $j=2$; are relevant for $\widetilde{A}_{i}^{k}$ and $\widetilde{B}_{i}{ }^{k}$ triangular fuzzy numbers. They characterize the findings for the importance degree and satisfaction degree, correspondingly, from Group 1, which is the OXYS group. The same is conducted as well for the Group 2 [ASOS], represented by $\widetilde{C}_{i}^{k}$ importance degree and $\widetilde{D}_{i}^{k}$ satisfaction degree of etail quality attributes having as an outcome brand loyalty types. In all cases $k$ and $j$ are constants [meaning $k=\underset{\widetilde{A}}{4}$, and $j=2$ ], we simplify the mathematical symbols and substitute $\widetilde{A}_{i}^{k}$ to $\widetilde{A}_{i}, \widetilde{B}_{i}^{k}$ to $\widetilde{B}_{i}, \widetilde{C}_{i}^{k}$ to $\widetilde{C}_{i}$ and $\widetilde{D}_{i}^{k}$ to $\widetilde{D}_{i}$.

For the fuzzification procedure the raw information gathered from the focus groups is needed and linguistic terms are converted into fuzzy sets: $\widetilde{A}_{i}=\left(a_{1}, a_{2}, a_{3}\right)$ $; \widetilde{B}_{i}=\left(b_{1}, b_{2}, b_{3}\right) ; \widetilde{C}_{i}=\left(c_{1}, c_{2}, c_{3}\right) ; \widetilde{D}_{i}=\left(d_{1}, d_{2}, d_{3}\right)$. Using the fuzzy importance degree is presented as the membership scores, being: very unimportant $[0,0,2]$, unimportant $[0,2,4]$, fair $[2,4,6]$, important $[4,6,8]$ and very important $[6,8,8]$. The coordinates next to the linguistic term represent the triangular fuzzy numbers of the importance degree.

Figure 4.: The consumer's linguistic term of Importance in fuzzy set
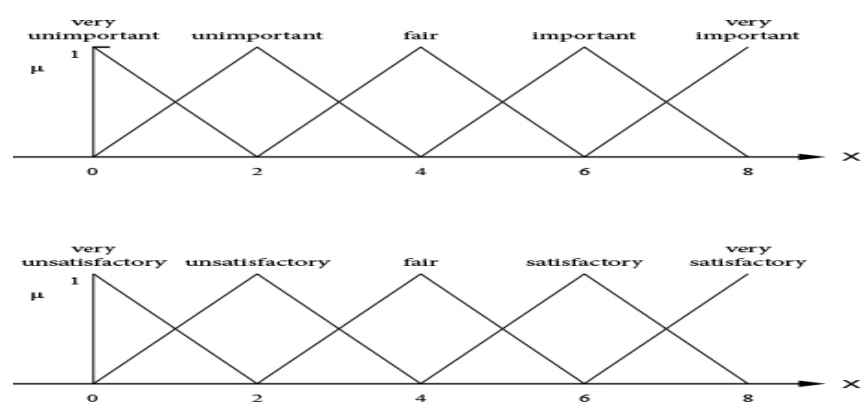

Source: Chien and Tsai (2000).

The satisfaction degree in linguistic terms has been proposed from Chien and Tsai (2000), presented in Figure 4. the scales are: very unsatisfactory $[0,0,2]$, unsatisfactory $[0,2,4]$, fair $[2,4,6]$, satisfactory $[4,6,8]$ and very satisfactory $[6,8,8]$; representing the cases in Group 1 and Group 2. 
Figure 5.: The consumer's linguistic term of Satisfaction in fuzzy sets
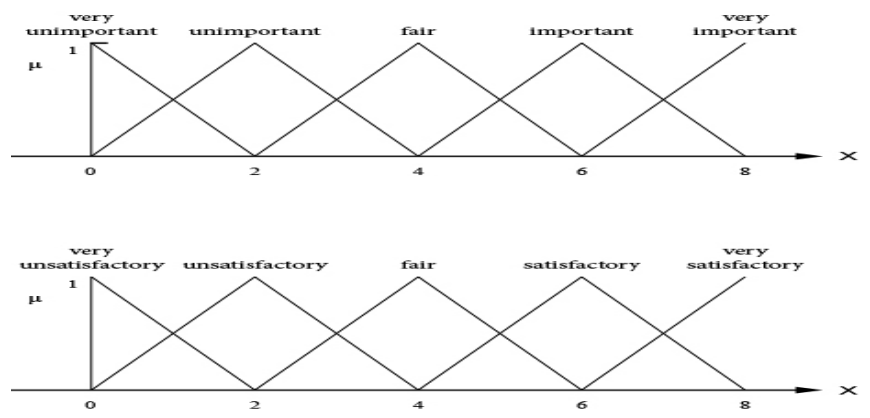

Source: Chien and Tsai (2000).

The transformation of linguistic terms from the raw data table to triangular fuzzy numbers was done through was used for $\widetilde{B}, \widetilde{C}$, and, $\widetilde{D}$. These equations set the membership score to understand the left [L] and right [R] of the membership function. There is a rule about the triangular fuzzy numbers that $a_{1}<a_{2}<a_{3}$, a rule which is valid as across all membership sets.

\subsection{Aggregating group opinions}

In order to reason from the group opinions, the study focuses on using theoretical frameworks, in order to aggregate group opinions for each condition related to the etail quality attributes and the two brand loyalty types: the latter considered as the outcome of the study. The aggregation of group opinions is conducted through equations (6) - (9). (Bojadziev and Bojadziev 2007), for each condition: for Group 1 importance degree denoted by $\widetilde{A}$ and satisfaction degree denoted by $\widetilde{B}$. The same rule is applied as well for Group 2, importance degree denoted by $\widetilde{C}$ and satisfaction degree denoted by $\widetilde{D}$. The graphical representation of the theory behind aggregating group opinions can be found at Figure 2.

$$
\begin{aligned}
& \widetilde{A}=A_{\text {ave }}=\frac{\widetilde{A}_{1}+\widetilde{A}_{2}+\ldots+\widetilde{A}_{n}}{n}=\frac{\left(\sum_{i=1}^{n} a_{1}^{(i)}, \sum_{i=1}^{n} a_{2}^{(i)}, \sum_{i=1}^{n} a_{3}^{(i)},\right)}{n}=\left(a_{1}, a_{2}, a_{3}\right) \\
& \widetilde{B}=B_{\text {ave }}=\frac{\widetilde{B}_{1}+\widetilde{B}_{2}+\ldots+\widetilde{B}_{n}}{n}=\frac{\left(\sum_{i=1}^{n} b_{1}^{(i)}, \sum_{i=1}^{n} b_{2}^{(i)}, \sum_{i=1}^{n} b_{3}^{(i)},\right)}{n}=\left(b_{1}, b_{2}, b_{3}\right) \\
& \widetilde{C}=C_{\text {ave }}=\frac{\widetilde{C}_{1}+\widetilde{C}_{2}+\ldots+\widetilde{C}_{n}}{n}=\frac{\left(\sum_{i=1}^{n} c_{1}^{(i)}, \sum_{i=1}^{n} c_{2}^{(i)}, \sum_{i=1}^{n} c_{3}^{(i)},\right)}{n}=\left(c_{1}, c_{2}, c_{3}\right) \\
& \widetilde{D}=D_{\text {ave }}=\frac{\widetilde{D}_{1}+\widetilde{D}_{2}+\ldots+\widetilde{D}_{n}}{n}=\frac{\left(\sum_{i=1}^{n} d_{1}^{(i)}, \sum_{i=1}^{n} d_{2}^{(i)}, \sum_{i=1}^{n} d_{3}^{(i)},\right)}{n}=\left(d_{1}, d_{2}, d_{3}\right)
\end{aligned}
$$


After running the analysis, the results for the condition "importance degree" in Group $1 A_{\text {ave }}$; in Group $2 C_{\text {ave }}$. With regards to the satisfaction degree we have $B_{\text {ave }}$ for Group 1; and $C_{\text {ave }}$ for Group 2.

\subsection{Strong or weak eTail Quality attributes}

In order to understand which etail Quality attribute is sufficient for the outcome to happen; meaning the behavioral intents, the measurement through strong or weak attribute analysis is used. Considering that this study measurements are based on the importance and satisfaction degree, it is considered that satisfaction degree to be the outcome that signifies the relation between etail attributes and brand loyalty types to happen. So, if the satisfaction degree for a given etail Quality attribute is greater than the importance degree of the same attribute, I say that the attribute is strong related to the specific brand loyalty type; and the opposite.

To find out the strong or weak attribute the procedure of comparing the group opinions is used(Chen 1996). The average triangular fuzzy numbers $\widetilde{A}=\left(a_{1}, a_{2}, a_{3}\right)$ and $\widetilde{B}=\left(b_{1}, b_{2}, b_{3}\right)$ for the importance and satisfaction degree, individually, corresponding to Group 1 responses; and $\widetilde{C}=\left(c_{1}, c_{2}, c_{3}\right)$ and $\widetilde{D}=\left(d_{1}, d_{2}, d_{3}\right)$ for the importance and satisfaction degree, individually, corresponding to Group 2 responses. These averages are applied to equations (10) and (11).

$$
\begin{aligned}
& v_{A}=\left(a_{1}+2 a_{2}+a_{3}\right) / 4 \\
& v_{B}=\left(b_{1}+2 b_{2}+b_{3}\right) / 4 \\
& v_{\text {Group } 1}=v_{B}-v_{A}
\end{aligned}
$$

Equation (12) measures the difference in importance degree and satisfaction degree for each etail Quality attribute affecting brand loyalty types, accordingly, within Groupı. The same procedure is followed for Group2 responses.

For the two groups, we get the difference scores between the importance degree and satisfaction degree symbolized as $V_{\text {Group } 1}$ and $V_{\text {Group } 2}$, for every single etail quality attribute related to the types of brand loyalty.

- Ruleı: If $v>0$; the satisfaction degree is greater than the importance degree, and so the etail quality attribute is considered strong for the specific outcome to happen.

- Rule2: If $v<0$ than the satisfaction degree is smaller than the importance degree. Once we get a score as this, we consider the attribute weak for the outcome to happen.

- Rule3: If $v=0$, means that the attribute has been considered at the same level of importance and satisfaction for the outcome. In this study we have no such results. 
Table 1.: Strong or Weak etail quality attributes for the outcome

importance degree of website design for paying a price premium

satisfaction degree of website design to urge you into paying a price premium

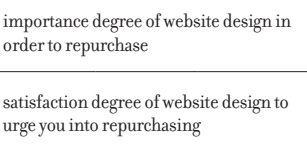

importance degree of fulfillment/ reliability for paying a price premium

satisfaction degree of fulfillment/ reliability to urge you into paying a price premium

\begin{tabular}{|l|}
\hline $\begin{array}{l}\text { importance degree of fulfillment/ } \\
\text { reliability in order to repurchase }\end{array}$ \\
\hline $\begin{array}{l}\text { satisfaction degree of fulfillment/ } \\
\text { reliability to urge you into repurchasing }\end{array}$ \\
\hline
\end{tabular}

importance degree of security/privacy for paying a price premium

satisfaction degree of security/privacy to urge you into paying a price premium

importance degree of security/privacy in
order to repurchase

importance degree of customer service for paying a price premium

satisfaction degree of customer service to urge you into paying a price premium

importance degree of customer service in order to repurchase

satisfaction degree of customer service to urge you into repurchasing
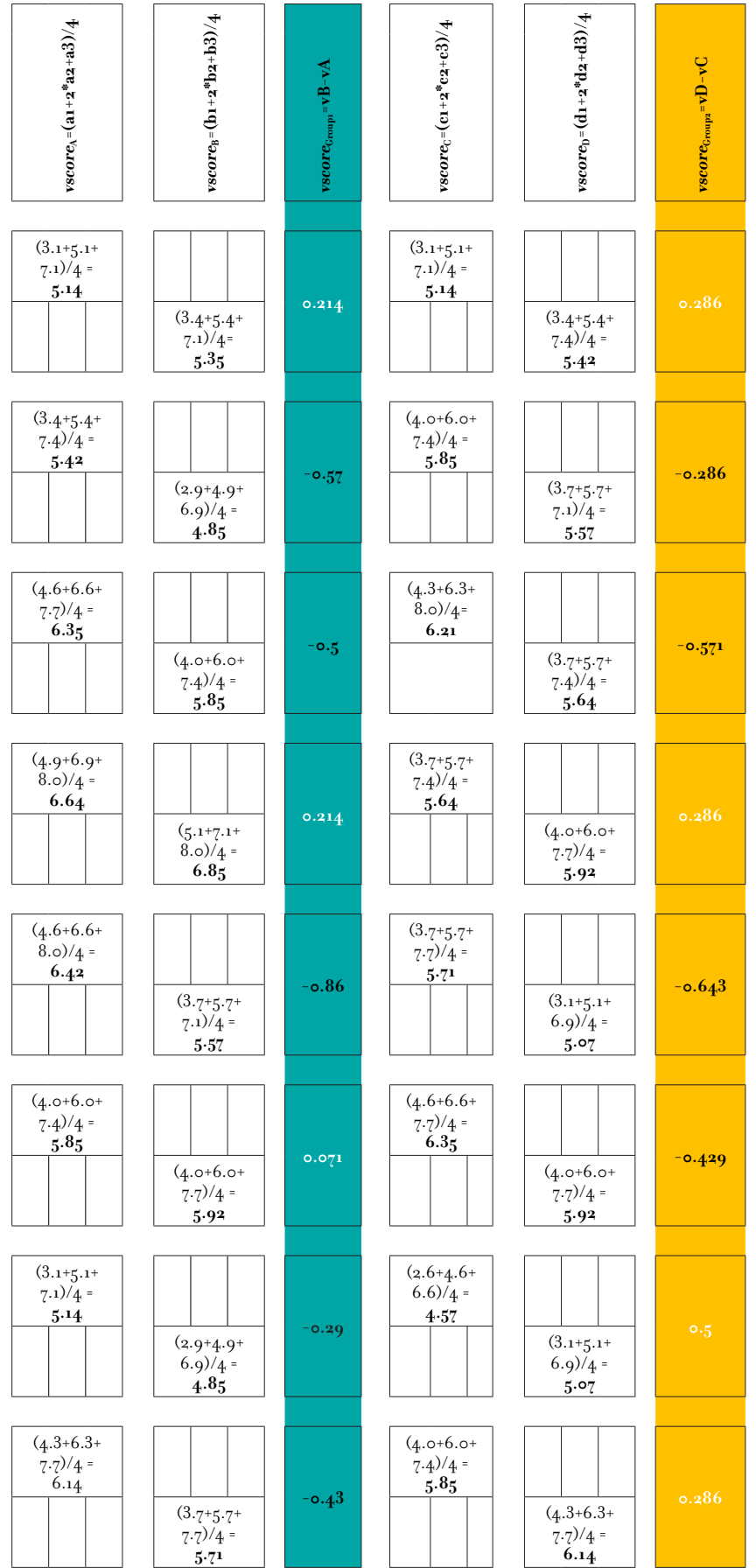

Source: Authors. 
Figure 6.: Graphic for the Strong and weak etail quality attributes for the outcome

\section{Difference between satisfaction and importance degree of each etail quality attribute and the two brand loyalty outcomes}

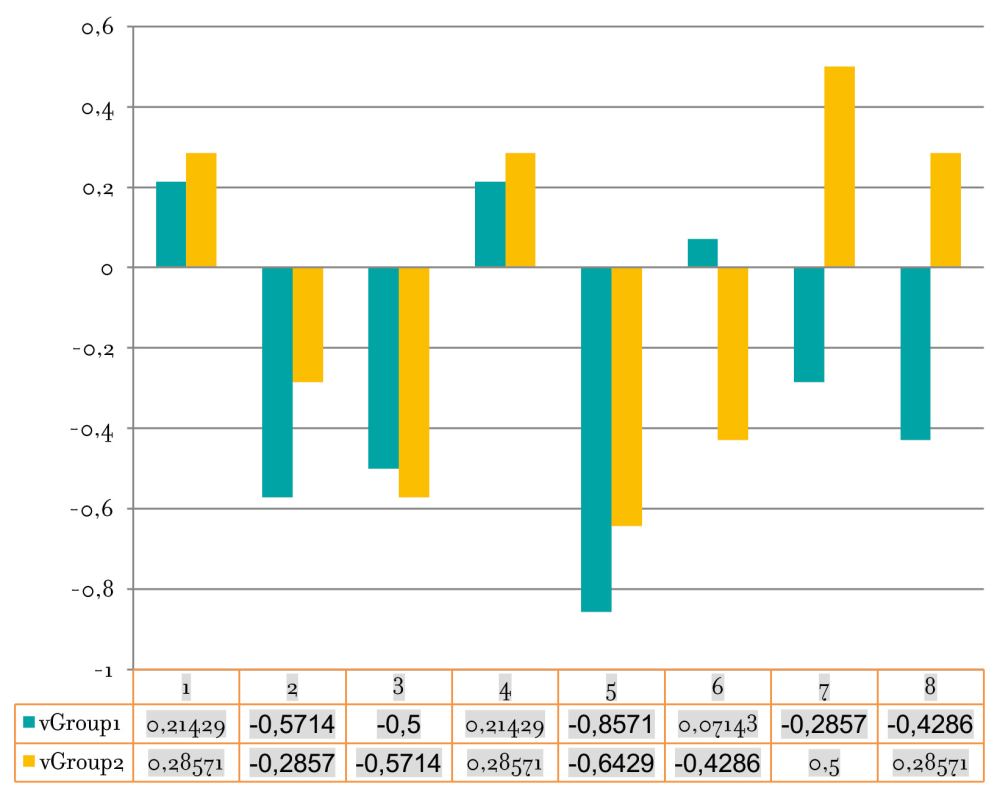

Source: Authors.

In the $\mathrm{X}$-axis of the diagram, the difference between satisfaction degree and importance degree for every attribute connected to the outcome is found; attributes are

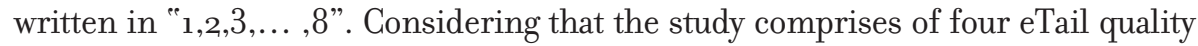
attributes and two brand loyalty outcomes, we have an overall representation of eight combinations, for each group that was studied.

\subsection{Defuzzifing sets}

During the defuzzification procedure we focus on the v scores that are greater than the value o, because these scores have shown that the given attribute is sufficient for the outcome to happen. Considering that in both groups, we have found positive scores for the website design attribute towards paying a price premium and reliability/fulfillment for the outcome of repurchasing we present the average weighted scores in approximate linguistic terms. 
Table 2.: Defuzzification scores

\begin{tabular}{|c|c|c|c|c|}
\hline \multicolumn{5}{|c|}{ Defuzzifying membership scores into percentages of membership } \\
\hline & & vscores & Important & Fair \\
\hline \multirow[t]{2}{*}{$\begin{array}{l}\text { importance degree of website } \\
\text { design for paying a price } \\
\text { premium }\end{array}$} & $\begin{array}{r}\text { OXYS } \\
\text { Group 1 }\end{array}$ & $5 \cdot 14286$ & $57 \cdot 14 \%$ & $42.86 \%$ \\
\hline & & vscores & Satisfactory & Fair \\
\hline \multirow[t]{2}{*}{$\begin{array}{l}\text { satisfaction degree of website } \\
\text { design to urge you into paying a } \\
\text { price premium }\end{array}$} & $\begin{array}{r}\text { OXYS } \\
\text { Group } 1\end{array}$ & 5.35714 & $67.86 \%$ & $32.14 \%$ \\
\hline & & vscores & Importance & Fair \\
\hline \multirow[t]{2}{*}{$\begin{array}{l}\text { importance degree of website } \\
\text { design for paying a price } \\
\text { premium }\end{array}$} & $\begin{array}{r}\text { ASOS } \\
\text { Group } 2\end{array}$ & $5 \cdot 14286$ & $57 \cdot 14 \%$ & $42.86 \%$ \\
\hline & & vscores & Satisfactory & Fair \\
\hline \multirow[t]{2}{*}{$\begin{array}{l}\text { satisfaction degree of website } \\
\text { design to urge you into paying a } \\
\text { price premium }\end{array}$} & $\begin{array}{r}\text { ASOS } \\
\text { Group } 2\end{array}$ & $5 \cdot 4,2857$ & $71.43 \%$ & $28.57 \%$ \\
\hline & & vscores & Important & $\begin{array}{r}\text { Very } \\
\text { Important }\end{array}$ \\
\hline \multirow[t]{2}{*}{$\begin{array}{l}\text { importance degree of } \\
\text { fulfillment/reliability in order } \\
\text { to repurchase }\end{array}$} & $\begin{array}{r}\text { OXYS } \\
\text { Group } 1\end{array}$ & $6.64,286$ & $32.14 \%$ & $67.86 \%$ \\
\hline & & vscores & Satisfactory & $\begin{array}{r}\text { Very } \\
\text { Satisfactory }\end{array}$ \\
\hline \multirow[t]{2}{*}{$\begin{array}{l}\text { satisfaction degree of } \\
\text { fulfillment/reliability to urge } \\
\text { you into repurchasing }\end{array}$} & $\begin{array}{r}\text { OXYS } \\
\text { Group } 1\end{array}$ & 6.85714 & $42.86 \%$ & $57.14 \%$ \\
\hline & & vscores & Important & Fair \\
\hline \multirow[t]{2}{*}{$\begin{array}{l}\text { importance degree of } \\
\text { fulfillment/reliability in order } \\
\text { to repurchase }\end{array}$} & $\begin{array}{r}\text { ASOS } \\
\text { Group } 2\end{array}$ & 5.64286 & $82.14 \%$ & $17.86 \%$ \\
\hline & & vscores & Satisfactory & Fair \\
\hline $\begin{array}{l}\text { satisfaction degree of } \\
\text { fulfillment/reliability to urge } \\
\text { you into repurchasing }\end{array}$ & $\begin{array}{r}\text { ASOS } \\
\text { Group } 2\end{array}$ & 5.92857 & $96.43 \%$ & $3.57 \%$ \\
\hline
\end{tabular}

Source: Authors.

\subsubsection{Website design towards paying a price premium for the local and global brand}

In order to better understand the implications of this finding, the study defuzzifies the v scores by running a quick analysis on the distance between the two closest membership scores where the given $\mathrm{v}$ score has fallen. The values are represented in percentages. The formula used in this study, has been proved as a decent method in defuzzifying triangular fuzzy numbers in social sciences (Chien and Tsai 2000, Bojadziev 
and Bojadziev 2007). Taking vA, vB, vC and vD scores as the weighted averages for the triangular fuzzy numbers representing the importance degree and satisfaction degree for each eTail quality attribute; The vA and vB scores are extracted in the relation between website design towards paying a price premium in Group 1, for the importance degree, the vAscore is 5.14286 , corresponding to $57.14 \%$ into the membership score of being Important and 42.86\% into being a member of the set Fair. Whereas for the satisfaction degree the v score is $5.357^{1} 4$, corresponding to $67.86 \%$ into being a member of the set Satisfactory and 32.14\% in being a member of the set Fair.

This finding leads to understand that website design is sufficient for the outcome of paying a price premium for the local brand [OXYS] to happen. Since the satisfaction degree is greater than the importance degree.

In Group 2, for the importance degree, the vG score is 5.14286 , corresponding to $57.14 \%$ into the membership score of being Important and $42.86 \%$ into being a member of the set Fair. Whereas for the satisfaction degree for the vD score is $5 \cdot 42857$ corresponding to a $71.43 \%$ into being a member of the set Satisfactory and $28.57 \%$ in being a member of the set Fair.

\subsubsection{Fulfillment and reliability towards repurchasing from the same brand}

To better understand how the v scores are ranked, we defuzzify vA, vB, vC and vD scores for the importance degree and satisfaction degree of the fulfillment/reliability attribute towards repurchasing from the same brand, individually for the two groups. In Group 1 , for the importance degree, the vA score is 6.64286, corresponding to a $67.86 \%$ into the membership score of being Important and $32.14 \%$ into being a member of the set Very Important. Whereas for the satisfaction degree presented by the $\mathrm{B}$ score is $6.857^{14}$, corresponding to a $57.14 \%$ into being a member of the set Satisfactory and 42.86\% in being a member of the set Very Satisfactory. In Group 2, for the importance degree, the vG score is $5.64,286$, corresponding to a $82.14 \%$ membership score of being Important and $17.86 \%$ into being a member of the set Fair. Whereas for the satisfaction degree the $\mathrm{vD}$ score is 5.92857 corresponding to a $96.43 \%$ into being a member of the set Satisfactory and $3.57 \%$ in being a member of the set Fair.

With the defuzzification procedure, the weighted average $\mathrm{v}$-scores are now converted into linguistic terms. This analysis allows the study to be more objective with regards to the scales with which the data was collected.

\section{CONCLUSIONS \& MANAGERIAL IMPLICATIONS}

There are three basic questions that the study aims to provide an answer: [i] Which are the strong eTail quality attributes that impact behavioral intents regardless of where a brand is local or global, in this case OXYS vs ASOS brands? [ii] Which 
are the strong eTail Quality attributes that impact behavioral intents when consumers buy from a local brand, in this case OXYS? And [iii] Which are the strong eTail Quality attributes that impact behavioral intents when consumers buy from a global brand, in this case ASOS?

Attributes that are considered sufficiently strong towards the outcome to happen in both the groups [regardless of being local or global] have been found to be:

\subsection{Website design towards paying a price premium for the OXYS \& ASOS brand}

Based on the cases that were studied; being aware of the brand or not being aware of the brand has not much influence in terms of paying a price premium for an e-commerce platform that offers a website design which is considered great by the user. Characteristics of a great website design are: great look, user friendly and easy to navigate, fast loading of pages and finally offering convenience. These findings can be enforced through previous literature on website design and the satisfaction from a transaction, which relates to brand loyalty intentions. (Rosen, 2004), points out that a well-designed site has a number of beneficial impacts, such as trust and confidence in the company as well as building on the image, functionality, and usefulness. Alongside these beneficial it can as well inform visitor to the company's range of products and services and reasons to come back again (Toufaily, Ricard and Perrien 2013). According to Pastrick (1997), offering e-commerce website designs which are fast, uncluttered and easy-to-navigate has statistically proven to offer pleasure and satisfaction for the website surfer. The cases that I studied, report to perceive that website design is a member of the set Satisfactory by 67.86\% in Group 1 and $7_{1} .4,3 \%$ in Group 2. This finding based on the theory of fuzzy sets (Zadeh 1965), appears to be sufficient for the price premium paying outcome to happen. Even though, website design has been studied redundantly from previous researches, there are still strong researches showing that it still remains one of the main dimensions of online service quality that impact loyalty (Collier and Bienstock 2015)

\subsection{Fulfillment and reliability towards repurchasing from the same brand}

In this study, fulfillment and reliability was defined with these elements: the company takes a special care on the product description and the compatibility with the products that will be shipped; a set timing of the dispatch and shipping process, and the opportunity to receive a new product if the product that was sent appears to be defective.

Based on the analysis that we conducted it is proved that an e-commerce platform that offers fulfillment and reliability services as mentioned above are predis- 
posed on pushing customers to repurchase from the same brand either in the case of OXYS or ASOS in the future. According to Jiang and Rosenbloom (2005) the satisfaction related to the delivery timing and reliability appears to have a great influence on the overall customer satisfaction as well as the grows the return intention in order to purchase from the same brand. According to Lee and Lin (2005), the "reliability dimension is a significant predictor of overall service quality, customer satisfaction and purchase intentions in online shopping." The cases that we studied, report to perceive that fulfillment/reliability is a member of the set Very Satisfactory by $57.14 \%$ in Group 1 and in the set Satisfactory $96.43 \%$ with regards to Group 2.

With regards to the analysis towards the eTail Quality attributes that impact behavioral intents towards a global brand customer service appears to be sufficient for both the outcomes: paying a price premium and repurchasing in coming occasions. Customer service expresses the relationship between the customer and the company, if customers are satisfied with the service offered this link strengthens which results in greater perceptions of service quality. According to Sundharesalingam and Padmavathy (2016), for online businesses, the first ranked variable in retaining customers to increase the customer loyalty base was characterized the customer service. 


\section{REFERENCES}

Alpar, Paul. 1999. "Satisfaction with a web site: Its measurement, factors and correlates." In In Electronic Business Engineering, 271-287. Physica-Verlag HD.

ASOS. 2015. "About us." ASOS Accessed 02.02. http://www.asos.com/about/.

Bakos, Yannis. 1998. "The emerging role of electronic marketplaces on the Internet." Communications of the ACM 41 (8):35-42. doi: 10.1145/280324.280330.

Bojadziev, George., and Maria. Bojadziev. 2007. Fuzzy logic for business, finance, and management.: World Scientific Publishing Co.

Blut, M., Chowdhry, N., Mittal, V. and Brock, C., "E-Service Quality: A Meta-Analytic Review". Journal of Retailing, 91(4), (2015): 679-700

Chaffey, Dave. 2007. E-business and E-commerce Management: Strategy, Implementation and Practice.: Pearson Education.

Chen, Shyi-Ming. "Evaluating weapon systems using fuzzy arithmetic operations." Fuzzy sets and systems 77 (3), (1996): $265^{-2} 276$

Chien, Cheng-Ju., and Hui-Hua. Tsai. "Using fuzzy numbers to evaluate perceived service quality." Fuzzy Sets and Systems 116 (2), (2000): 289-300

Chiu, Sheng Yang. Sze Yin Ho, Jessica. 2015. "Local vs. Global Brands: Country-of-Origin's Effect on Consumer-based Brand Equity among Status-Seekers." Journal of Economics and Behavioral Studies 7 (3).

Christensen, Larry B., Burke. Johnson, and Lisa A. Turner. 2011. Research methods, design, and analysis.: Allyn \& Bacon.

Collier, J.E. and Bienstock, C.C., A conceptual framework for measuring e-service quality. In Creating and Delivering Value in Marketing, pp. 158-162. Springer International Publishing, Cham, 2015.

Culnan, Mary J., and Pamela K. Armstrong. 1999. "Information privacy concerns, procedural fairness, and impersonal trust: An empirical investigation." Organization science 10 (1), (2015): 104,-115

Dubois, Didier., and Henri. Prade. "A review of fuzzy set aggregation connectives." Information Sciences 36 (1), $(1985): 85^{-121}$

EM Steenkamp, Jan-Benedict, Rajeev Batra, and Dana LAlden. "How perceived brand globalness creates brand value." Journal of International Business Studies 34 (1), (2003): $5^{3-65}$

Friedman, Batya., Peter H. Khan Jr, and Daniel C. Howe. "Trust Online." Communications of the ACM 43 (12), (2000): $34-40$

Gustafsson, Anders, Janjaap Semeijn, Allard C. R. van Riel, Marcel J. H. van Birgelen, and Sandra Streukens. "E-services and offline fulfilment: how e-loyalty is created." Managing Service Quality: An International Journal 15 (2), (2005):182-194. doi: 10.1108/09604520510585361.

Hoffman, Donna L., Thomas P. Novak, and Marcos. Peralta. 1999. "Building consumer trust online." Communications of the ACM 42 (4):80-85. doi: 10.1145/299157.299175.

Jacoby, Jacob., and David. Kyner. "Brand loyalty vs. repeat purchasing behavior." Journal of Marketing Research: (1073): 1-9

Jiang, Pingjun., and Bert. Rosenbloom. "Customer intention to return online: price perception, attributelevel performance, and satisfaction unfolding over time." European Journal of Marketing 39 (1/2), (2005): 150-174 
Keller, Kevin Lane. 2012. Strategic Brand Management Building, Measuring, and Managing Brand Equity. Vol. 4: Prentice Hall.

Klir, George., and Bo. Yuan. Fuzzy sets and fuzzy logic. Vol. 4. New Jersey: Prentice Hall.

Lee, Gwo-Guang, and Hsiu-Fen Lin. 2005. "Customer perceptions of e-service quality in online shopping." International Journal of Retail \& Distribution Management 33 (2), (1995):161-176. doi: $10.1108 / 09590550510581485$.

Liu, Chang, and Kirk P. Arnett. "Exploring the factors associated with Web site success in the context of electronic commerce." Information \& Management 38 (1), (200): 23-33

Loiacono, Eleanor, Richard Watson, and Dale Goodhue. "WebQual: An Instrument for Consumer Evaluation of Web Sites." International Journal of Electronic Commerce 11 (3), (2007): 51-87 doi: 10.2753/ jec1086-4415110302.

McGovern, Gerry. "Content builds brands online." International Journal on Media Management 3 (4), (2001):198-201

Miyazaki, Anthony D., and Ana. Fernandez. "Consumer perceptions of privacy and security risks for online shopping." Journal of Consumer Affairs 35 (1), (2001): 27-44

Novak, Thomas., Donna L. Hoffman, and Yiu-Fai. Yung. 2000. "Measuring the customer experience in online environments: A structural modeling approach." Marketing Science 19 (1), (2000): 22

Oliver, Richard L. "Whence consumer loyalty?" Journal of Marketing. (1999): 33-44

Parasuraman, Anantharanthan. Zeithaml, ValarieA., and Leonard L. Berry. "A conceptual model of service quality and its implications for future research." Journal of Marketing, (1985): 41-50

Pan, Y., Sheng, S. and Xie, F.T., Antecedents of customer loyalty: An empirical synthesis and reexamination. Journal of Retailing and Consumer Services, 19(1), (2012): 150-158

Pastrick, Greg. "Secrets of great site design." InternetUser, (1997): 80-87

Peter, J. Paul., Gilbert A. Churchill Jr, and Tom J. Brown. "Caution in the use of difference scores in consumer research." Journal of Consumer Research. (1993): 655-662

Rihoux, Benoît., and Charles C. Ragin. 2009. Configurational comparative methods: Qualitative comparative analysis (QCA) and related techniques: Sage.

Roselius, Ted. "Consumer rankings of risk reduction methods." Journal of Marketing:56-61.

Rosen, Deborah E., and Elizabeth Purinton. 2004. "Website design." Journal of Business Research 57 (7), (1971):787-794. doi: 10.1016/so148-2963(02)oo353-3.

Roy, Rajat, and Ryan Chau. "Consumer-based brand equity and status-seeking motivation for a global versus local brand." Asia Pacific Journal of Marketing and Logistics 23 (3), (2011):270-284. doi: 10.1108/1355585111114.3213.

Schaffer, Eric. 2000. "A better way for Web Design." Information Week, 194.

Schefter, Phil., and Frederick. Reichheld. "E-loyalty: your secret weapon on the Web." Harward Business Review 78 (4), (2000): 105-113

Sharma, G. and Lijuan, W., "The effects of online service quality of e-commerce Websites on user satisfaction". The Electronic Library, 33(3), (2015): 468-4.85

Srinivasan, Srini S., Rolph. Anderson, and Kishore. Ponnavolu. "Customer loyalty in e-commerce: an exploration of its antecedents and consequences." Journal of Retailing 78 (1), (2002):41-50 
Sundharesalingam, P. and Padmavathy, S., "A Comparative Study on Customer Satisfaction and Retention Strategy in Public and Private Sector Banks." Asian Journal of Research in Social Sciences and Humanities, 6(4), (2016): 563-583

Tassabehji, Rana, and Inc. Ebrary. Applying E-commerce in business: SAGE Publications.

Toufaily, E., Ricard, L. and Perrien, J., 2013. "Customer loyalty to a commercial website: Descriptive meta-analysis of the empirical literature and proposal of an integrative model." Journal of Business Research, 66(9), (2003): 1436-1447

Wolfinbarger, Mary., and Mary C. Gilly. "eTailQ: dimensionalizing, measuring and predicting etail quality." Journal of Retailing 79 (3), (2003): 183-198. doi: 10.1016/soo22-4359(o3)०oo34-4.

Zadeh, Lotfi A. "Fuzzy sets." Information and control 8 (3), (1965): 338-353

Zadeh, Lotfi A. "Toward a perception-based theory of probabilistic reasoning with imprecise probabilities." Journal of statistical planning and inference 105 (1), (2002): 233-264

Zeithaml, Valarie A. "Consumer perceptions of price, quality, and value: a means-end model and synthesis of evidence." Journal of Marketing, (1988): 2-22

Zeithaml, Valarie A., Leonard L. Berry, and A. Parasuraman. "The Behavioral Consequences of Service Quality." Journal of Marketing 60 (2), (1996):31. doi: 10.2307/1251929.

Zhang, Yinlong, and Adwait Khare. "The Impact of Accessible Identities on the Evaluation of Global versus Local Products." Journal of Consumer Research 36 (3), (2009):524-537. doi: 10.1086/598794.

Zimmermann, Hans-Jürgen. 2001. Fuzzy set theory-and its applications.: Springer Science \& Business Media. 
